\title{
AC 2010-435: IMPLEMENTING A PROGRESSIVE APPROACH TO TANGIBLE AIRCRAFT DESIGN
}

\section{Matthew Rowland, Dept. of Civil \& Mechanical Engineerint at United States Military Academy}

MAJ Matthew Rowland graduated from the University of Washington in 1998 with a Bachelor of Science in Aeronautical and Astronautical Engineering. He earned a Master of Science degree in Aeronautical and Astronautical Engineering from the University of Washington in 2008. He has served in various command and staff positions during his Army career and during his tenure at USMA has course directed the aeronautical subdiscipline course for Aircraft Performance and Stability. He is the current faculty advisor for the SAE Design Build Fly team.

\section{Andrew Bellocchio, United States Military Academy}

MAJ Andrew Bellocchio earned is Bachelor of Science in Mechanical Engineering from the United States Military Academy as well as his Master of Science in Aerospace Engineering from Georgia Tech. He is an Army Aviator who has served in numerous command and staff positions during his Army career and was the course director for Aircraft Performance and Stability from 2007 to 2008 . He is currently serving the United States Army overseas. 


\title{
Implementing a Progressive Approach to Tangible Aircraft Design
}

\begin{abstract}
Implementation of an undergraduate aircraft design curriculum in a short aeronautical engineering course sequence can be challenging. Ideally, students need to be taught fundamental aircraft design material in a way that can easily be transitioned to a hands-on design project. The project should be both interesting and fun but also try to cover the entire design process from a conceptual standpoint to the preliminary design phase and finally expose them to the detailed manufacturing of a prototype for testing. As is often the case, time and resources are limited and much of the hands-on engineering education experience so valuable to a student is hard to achieve. While many students can and do receive this type of educational experience through a competitive capstone design project, it is arguably better that this is not the first time they are exposed to integrating and applying the material covered in an aeronautical engineering course sequence. This paper details how to make use of an inexpensive hands-on glider design project that can be integrated across a short undergraduate aeronautical engineering course sequence effectively educating students on the practical application of aircraft design. Through the individual design and construction of multiple balsa wood gliders over a two course sequence, each student can apply and correlate the various aspects of aircraft design with tangible, measureable results better preparing them to work as a team in support of a capstone project. While the use of balsa wood gliders in aerospace engineering is relatively common, this paper details how to apply a more robust design methodology that enhances a student's aircraft design education. The goal of the paper is to provide engineering educators with the documentation, analytical tools, and examples necessary to establish a glider design project within their own existing engineering courses. Some aircraft design aspects addressed are aircraft sizing, stability, configuration and layout, as well as performance parameters such as lift-to-drag ratio, wing loading, and range. Direct feedback on successful or unsuccessful design aspects are realized through class competitions using the individually constructed gliders and results are formalized in a report. The impact of the project on student capstone performance and its contribution to aircraft design education is assessed through student surveys and degree of capstone progress.
\end{abstract}

\section{Introduction}

For over fifteen years now instructors at the United States Military Academy (USMA) at West Point have made use of an inexpensive hands-on glider design project to practically apply aircraft design concepts covered in class. Through the years the project has evolved into a relatively simple but conceptually robust method in which students can practice implementing all aspects of aircraft design. Because the project is repeated over a short course sequence, lessons learned from early designs can be reinforced and expanded upon in a subsequent design allowing for improved performance and application of new more complex concepts. The current aerospace engineering short course sequence in the Mechanical Engineering Department at the United States Military Academy consists of two semesters, one at the junior level and the second at the senior level, that cover fundamentals of aerodynamics, aircraft performance and design, as well as static stability. Every student designs, builds, and flies a balsa wood glider in both 
courses with very similar design focused objectives. Each project $\left(1^{\text {st }}\right.$ then $2^{\text {nd }}$ semester $)$ is completed in about a week's time and allows students to develop some initial continuity and experience working with balsa wood construction that can be used again in a future project. Students are then able to focus more effort and energy on some more advanced concepts for their second design. Overall the design projects are nested in these courses to support the following mechanical engineering program outcomes of the institution:

Outcome \#1. An ability to identify and formulate engineering problems and apply knowledge of mathematics, science, and engineering along with creativity skills to solve those problems in mechanical engineering and Army contexts.

Outcome \#2. An ability to design and realize thermal and mechanical systems, components, or processes to meet the needs of the mechanical engineering discipline, the Army, or the nation.

\section{The Balsa Wood Glider -1st Design}

After covering fundamentals of aerodynamics and how they apply to aircraft wings students are given the assignment to design build and fly their first glider. They now understand some basics on how lift is produced, why an airfoil section is preferable to a flat plate, and are knowledgeable about such parameters and concepts as aspect ratio, taper ratio, wing twist, wing sweep etc. The objective of the first design is to simply design, build, and fly an efficient low speed glider with a minimum lift to drag ratio (L/D) of 6 . Constraints are minimal and allow students to be creative in their solution. The materials provided are very low cost and consist of the following:

- $36 \times 4 \times 3 / 32$ in. sheet of balsa (Thin Piece)

- $36 \times 3 \times 3 / 16$ in. sheet of balsa (Thick Piece)

- Cutting Board

- Exacto Knife

- Wood Glue / Epoxy.

- Sand Paper

Additionally, students are allowed to use scotch tape or masking tape, up to two of any U.S. currency coins for ballast in adjusting the center of gravity, and sand paper for smoothing of the wooden surfaces. Tape is restricted from being used to enhance aerodynamic surfaces or provide trim. This ensures students focus on sizing and design theory to try and achieve the maximum $\mathrm{L} / \mathrm{D}$ ratio. To allow for mistakes in construction on their first design, students may exchange damaged balsa wood for a new sheet; however, this is not an option in the second design in order to reinforce the planning and specificity required for completion of the detailed design phase. Robustness is emphasized to focus students on construction techniques and considerations so that they are more experienced and familiar with what works and what doesn't better preparing them for their second design attempt. 


\section{Glider Flight Test and Competition}

The first design attempt ends with a competition that measures the performance of each student's glider by measuring its maximum straight line distance perpendicular to a launch point from an 18 foot high balcony inside a gymnasium. The L/D achieved is easily calculated by dividing the range by the height, and only the best score is recorded after as many test flight attempts are deemed necessary. The results are widely varied at this point because of many different solutions. Some student solutions are based more heavily on engineering concepts discussed in class while others seem to largely have aesthetic values as a priority. The benefit of the initial competition is to expose students to the importance of construction challenges as well the inevitable testing and modification required of their original design to try and meet the L/D ratio requirement. Additionally students have fun competing against each other for bonus points and bragging rights. Table 1 shows a sample breakdown for scoring in the first design competition. The bottom line of the first design is to fundamentally begin to apply the concepts and get comfortable with the construction techniques of the balsa wood gliders while instilling and supporting a passion for design engineering. End of course data surveys from 2009 targeting student opinion of the first glider design project show support through an agreement scale of 1-5, five indicating strongest agreement. Students gave the first glider design project an agreement score of 4.2 as the assignment they would most like to keep as part of the course. Agreement scores were similar regarding how much students felt they learned from the glider design block and how well it fit in with course material and course objectives (agreement score of 4.0). Taking into consideration that you must attempt to normalize the agreement survey values these scores are still above average due to the fact that the highest score of any survey question was 4.6 and the lowest a 3.0 with a mean of 3.9.

Table 1. Sample Scoring Table for Glider Design I Competition

\begin{tabular}{|c|c|c|c|c|}
\hline \multicolumn{2}{|c|}{ Lift-to-Drag Ratio } & \multicolumn{2}{|c|}{ Robustness } & Production Quality \\
\hline \multicolumn{2}{|c|}{ (85 Points Maximum) } & \multicolumn{2}{|c|}{ (10 Point Maximum) } & (5 Points Maximum) \\
\hline $6+$ & 85 & Robust & 10 & \multirow{5}{*}{$\begin{array}{c}\text { Subjective: } \\
\text { Craftsmanship, } \\
\text { Aerodynamic Features (taper, } \\
\text { dihedral, rounded edges, etc), } \\
\text { A/C name prominently } \\
\text { displayed, fuselage artwork }\end{array}$} \\
\hline $5+$ & $76-85$ & \multirow{2}{*}{$\begin{array}{l}\text { Minor failure } \\
\text { (loose } \\
\text { components) }\end{array}$} & \multirow{2}{*}{5} & \\
\hline $4+$ & $68-76$ & & & \\
\hline $3+$ & $60-68$ & \multirow{2}{*}{$\begin{array}{l}\text { Critical failure } \\
\text { (fracture, } \\
\text { disintegration) }\end{array}$} & \multirow{2}{*}{0} & \\
\hline$<3$ & 60 & & & \\
\hline
\end{tabular}

\section{The Balsa Wood Glider $-2^{\text {nd }}$ Design}

With one glider already designed, built, and flown students enter the next course in the aerospace engineering sequence with some practically applied ideas on aircraft performance parameters not only from their own design experience but from the observed successes and failures of their peers as well. They remember who performed well and why as well as who failed and why. So far we must keep in mind much of these successes and failures have very little modeling or analytical calculation behind their design decisions. At this point the course curriculum focuses more specifically on the aircraft design process involving the conceptual, 
preliminary, and detailed design phases covered in the course texts: "Aircraft Performance and Design"1 and "Introduction to Flight." Fundamentals such as calculating the drag polar for an aircraft to determine its aerodynamic performance, and weight estimation with sizing parameters like wing loading, and tail volume ratios are addressed at length. An additional focus on static stability covered in Anderson's "Introduction to Flight", is also conducted with homework assignments and labs designed to gain familiarity with the governing equations involved. At the end of this course the $2^{\text {nd }}$ Glider Design project is issued but with a much more robust conceptual and preliminary design requirement. Students are provided with the "Glider Methodology" outlined in Appendix A to produce an analytical glider code used to design and optimize the performance of their balsa wood glider. The methodology details the use of the governing equations covered in class and the associated assumptions necessary for designing a balsa wood glider. When followed correctly and carefully, students are able to see how each governing equation ties in with the overall design of the aircraft and in the end are able to vary the specific design parameters to get a feel for how each affects the performance of the aircraft overall. The glider design methodology is the heart of the project that ties in all the concepts covered in class to show how they can apply to real world aircraft design. By requiring students to model their aircraft using software tools such as MATLAB or Microsoft Excel they not only study the methodology but become more familiar with the governing equations and how they are used to design and estimate the performance of their glider.

The same materials and criteria for the first glider design are used with the exception of the fact that the wingspan is now limited to 24 inches in order to ensure the solution possibilities are realistic for competition purposes. With their glider code developed, students make calculated design decisions based off this analytical tool and also rely on their previous experience from the first design when making decisions on construction. It is important to emphasize to the students that the developed glider code is only an analytical tool, not an exact measure, and must be used as such. While robust in the use of governing equations it is still subject to many assumptions and therefore subject to inaccuracies. For example the estimation of the coefficient of lift for a flat plate is .81 which may or may not be achieved in the actual glider design. Even well performing gliders fall short of the predicted performance range of the glider code. This further illustrates the importance of understanding the limitations of your computer model and where practical engineering judgment, knowledge, and intuition come in to play in determining a viable solution. In other words you can't blindly follow your code. The student's final performance of their glider and the decisions that drove them to their final design are summarized and documented in a final report.

\section{Second Glider Competition and Results}

The competition for the second design holds slightly higher standards than the first in that it incorporates a lateral drift performance category. This serves to place additional emphasis on lateral and directional stability considerations for the students design. Table 2 shows a sample grading criteria for the $2^{\text {nd }}$ design competition incorporating this scoring category. 
Table 2. Sample Scoring Table for Glider Design II Competition

\begin{tabular}{|c|c|c|c|}
\hline \multicolumn{2}{|c|}{$\begin{array}{c}\text { Lift-to-Drag Ratio } \\
\text { (100 Points Maximum) }\end{array}$} & \multicolumn{2}{|c|}{$\begin{array}{c}\text { Lateral Drift } \\
\text { (Off the centerline axis) } \\
\text { (20 Points Maximum) }\end{array}$} \\
\hline $6+$ & 80 & $0-15 \%$ & 20 \\
\hline $5+$ & $72-80$ & $16-25 \%$ & 15 \\
\hline $4+$ & $64-72$ & $26-40 \%$ & 10 \\
\hline $3+$ & $56-64$ & $>40 \%$ & 5 \\
\hline$<3$ & 55 & & \\
\hline
\end{tabular}

The end product of the $2^{\text {nd }}$ competition on average yields better L/D ratio performance results than the first competition. In the most recent comparison, 19 of the 26 performing gliders significantly improved the L/D ratio over their first design. However, while the overall improvement is noticeable we must be careful not to give the improvements too much weight as in several cases there is little consistency between the strategies of the first and second design for each student. In other words, some students stick to what they thought worked while others tried things that were far different, thus it is somewhat harder to measure the effectiveness of the glider design projects based solely on successive glider performance. This should not however take away from the value of the progressive approach. Even for the minority of students whose performance of their second glider was the same or worse than their first, the exercise is still highly valuable. This is because they were able to apply the engineering design process in a much more robust way using the governing equations associated with aircraft design learned in class while practically testing and observing the results of their decisions.

\section{Best Practices}

While the glider methodology in Appendix A yields the analytical tool shown in Appendix B allowing students to make design decisions there are many other things that can be done to optimize one's glider. Some good advice comes from the article "Design of Balsa Wood Gliders: A lesson in the engineering process"3 and helps students understand and make the most of the project they are required to complete. For example the article discusses qualitative construction techniques as well as testing methods and modifications that can be made once the aircraft is flown. Additionally, because the gliders are launched by hand there is something to be said for proper throwing technique. The gliders are designed to fly at speeds ranging from approximately 15-20 fps. Thus, if students find their glider climbing sharply upon release they are most likely throwing them too hard. Likewise, too soft of a release will cause the glider to stall and pitch down. Also, sanding of the leading edges and the fuselage to achieve as smooth of a surface as possible is recommended and beneficial, especially since many of the drag approximations for performance are based on laminar flow while in reality the flow is most likely transitional. Finally, establishing a positive angle of incidence or positive tail setting angle with respect to the horizontal stabilizer is advisable to ensure positive static stability. However, if students can design in the ability to adjust or "fine tune" this tail setting angle during flight test it can be a great advantage in trimming the aircraft for stable performance thus increasing the maximum range achieved during the competition. 


\section{Student Course Assessments and Evaluations}

Assessment of the impact of the glider design projects on students learning and their understanding of aircraft is accomplished through a survey of the same students after they have completed both courses and both projects as well as begun to participate in various capstone projects. Using the same agreement scale discussed earlier yields some expected results. First, when asked if the overall glider design projects contributed to their understanding of the aircraft design process, $83 \%$ of the students agreed with an average score of 3.9. It should be noted that within the population there were some students who performed poorly because they were unable to succeed in getting their code to work due to competing demands for time etc. It is understandable that those who were unable to complete the first portion of the assignment would stand to reap the least benefit from the project and would vote accordingly in their survey. One of the challenges with these projects as an instructor will be to ensure a fair amount of time is allotted for students to complete their code to ensure maximum benefit. In this example, an entire lesson was devoted as a design studio allowing for students to bring in their code for additional instruction, troubleshooting, and debugging etc.

When asked if the familiarity gained in completing the first glider project enhanced their performance on the second project, the survey yielded an agreement score of 3.7 with $65 \%$ of the students being in agreement. Although it is still a majority it should be noted that the score would most likely be higher had the students design strategies with their first glider design been more in line with the design of their second. This is somewhat a point of instructor preference in terms of how much a student is allowed to try something totally new with their second design verses try and improve their original.

Survey results yielded 100\% agreement (score of 5.0) regarding the glider project's value in preparing students for aircraft design related capstone projects such as the SAE Aero Design competition where students must design build and fly an aircraft to lift a heavy payload. While this result is not surprising since the glider project directly relates to this specific capstone effort, it is positive affirmation that the glider project is well suited and aligned with the concepts needed to design aircraft beyond small balsa wood gliders etc. Actual performance data from the capstone teams and its correlation to the glider projects will be available after the competition in April of 2010.

\section{Conclusion}

Engineering students using a progressive approach to aircraft design not only have the experience of modeling and sizing their glider in a conceptual design phase, but they also make decisions based on their own analytical model, their intuition, and previous glider design experience. This allows them to complete their preliminary design phase, and determine the exact parameters and construction methods necessary in completing the detailed design of an aircraft. Combining the design of two separate gliders in conjunction with the aerospace engineering curriculum offers students a design education and foundation that they can then apply to more extensive capstone projects such as the SAE Design, Build, Fly competition. Students gain experience working with the design parameters associated with aircraft and are introduced to the design process and its framework better preparing them for success. 
Specifically, the use of the progressive approach and the glider design methodology outlined in this paper gives students a stepping stone to begin analytical modeling of more advanced capstone projects thus enabling teams to better support and document their capstone design decisions. It is my hope that engineering educators will use this as a tangible, fun, and inexpensive way to enhance the education of their students in the fundamentals of aircraft design.

\section{Bibliographic Information}

${ }^{1}$ Anderson, John D. Jr., Aircraft Performance and Design,New York: McGraw-Hill, 1999

${ }^{2}$ Anderson, John D. Jr., Introduction to Flight, Sixth Edition, New York: McGraw-Hill, 2008

${ }^{3}$ Kamprath, Michael F., Design of Balsa Wood Gliders: A Lesson in the Engineering Process, Univeristy of Michigan, Ann Arbor: Michigan Space Grant Consortium, available at: http://sgc.engin.umich.edu/kids/gliderdesign.shtml, 10 December 2009

${ }^{4}$ Spedding, G.R. and McArthur, J., Span Efficiencies of Wings at Low Reynolds Numbers, Journal of Aircraft, JanFeb 2010: 120-128 


\section{APPENDIX A. Glider Methodology}

\section{Design Parameters}

L fuselage length (in)

$\mathrm{H}$ fuselage height (in)

b main wing span (in)

$\mathrm{c}_{\mathrm{r}} \quad$ main wing root chord (in)

$\lambda \quad$ main wing taper ratio

$\mathrm{x}_{\text {wing }}$ distance from nose leading edge to main wing leading edge (in)

$\mathrm{AR}_{\mathrm{VT}}$ vertical tail aspect ratio

$\mathrm{x}_{\text {ballast }}$ location of coin ballast (in)

$\mathrm{m}_{\text {ballast }}$ mass of coin ballast (slugs)

$\mathrm{V}_{\text {trim }} \quad$ trim velocity $(\mathrm{ft} / \mathrm{s})$

\section{$\underline{\text { Assumptions }}$}

1. Standard Sea Level pressure, density, viscosity for air.

2. Aircraft operates in Steady Gliding Flight: Lift $=$ Weight

3. Horizontal Tail Volume Ratio $=1$ (Approximation

4. Vertical Tail Volume Ratio $=.04$

5. Airfoil is a flate plate (Thin Balsa Sheet) thus maximum $\mathrm{C}_{\mathrm{L}}=.81$

6. Trim Velocity is constant (Approx 15-20 fps)

7. Drag addition from Coins and tape / extra glue is negligible

8. Aerodynamic Center of the Horizontal Tail is at the quarter chord

9. Aerodynamic Center of the Vertical Tail is at the quarter chord

10. Average chord length is based off of rectangular wing, tail, and fuselage geometry

11. Weight of the Glue is negligible

12. Center of Gravity of the vertical and horizontal tail is located at the half chord length

13. Oswald Efficiency Factor is 0.8 for High Wing and .6 for Low Wing. Note: Recent Literature by Spedding and McArhur ${ }^{4}$ predicts a much lower Oswald Efficiency Factor at $\operatorname{Re}<5 \times 10^{5}$

14. Balsa wood is homogenous and therefore has constant density

15. Taper Ratio is constant for main wing and tail $\lambda=\lambda_{\mathrm{HT}}=\lambda_{\mathrm{VT}}$

16. Assume the wing, tail, and fuselage as 2-dimension flat plates with two wetted sides to each component. ( $\left.S_{\text {wet }}=2 S\right)$. 


\section{Main Wing}

\section{Wing Geometry}

$$
\begin{aligned}
& \bar{c}=\frac{2}{3} c_{r}\left(\frac{1+\lambda+\lambda^{2}}{1+\lambda}\right) \\
& c_{t}=\lambda c_{r} \\
& S=b \frac{c_{r}+c_{t}}{2} \\
& A R=\frac{b^{2}}{S}
\end{aligned}
$$

where

$\begin{array}{ll}\bar{c} & \text { is main wing mean chord (in) } \\ \mathrm{c}_{\mathrm{t}} & \text { is main wing tip chord (in) } \\ \mathrm{S} & \text { is planform area }\left(\mathrm{in}^{2}\right) \\ \mathrm{AR} & \text { is aspect ratio }\end{array}$

\section{Sweep Angle}

$$
A=\tan ^{-1}\left(\frac{\frac{c_{r}-c_{t}}{2}}{b / 2}\right)
$$




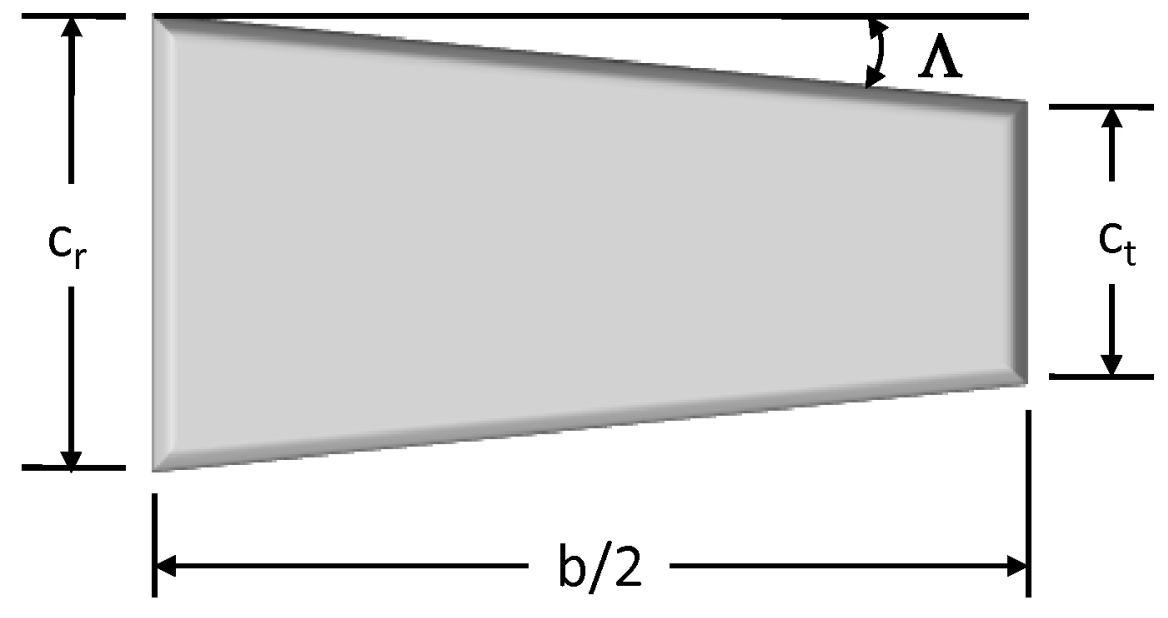

Figure 1: Taper Ratio

\section{Wing Aerodynamic Center}

$$
\begin{aligned}
& h_{a c \text { wing }}=\frac{x_{\text {wing }}+\frac{b}{6}\left(\frac{1+2 \lambda}{1+\lambda}\right) \tan \Lambda+0.25 \bar{c}}{\bar{c}} \\
& x_{\text {acwing }}=h_{a c \text { wing }} \bar{c}
\end{aligned}
$$

where
$\mathbf{X}_{\text {wing }}$
is the distance from nose to wing's leading edge (in)
$\mathrm{h}_{\mathrm{ac} \text { wing }}$
is the non-dimensional distance from nose to wing's leading edge
$\mathrm{X}_{\mathrm{ac} \text { wing }}$ is the distance from nose to wing's aerodynamic center (in) 


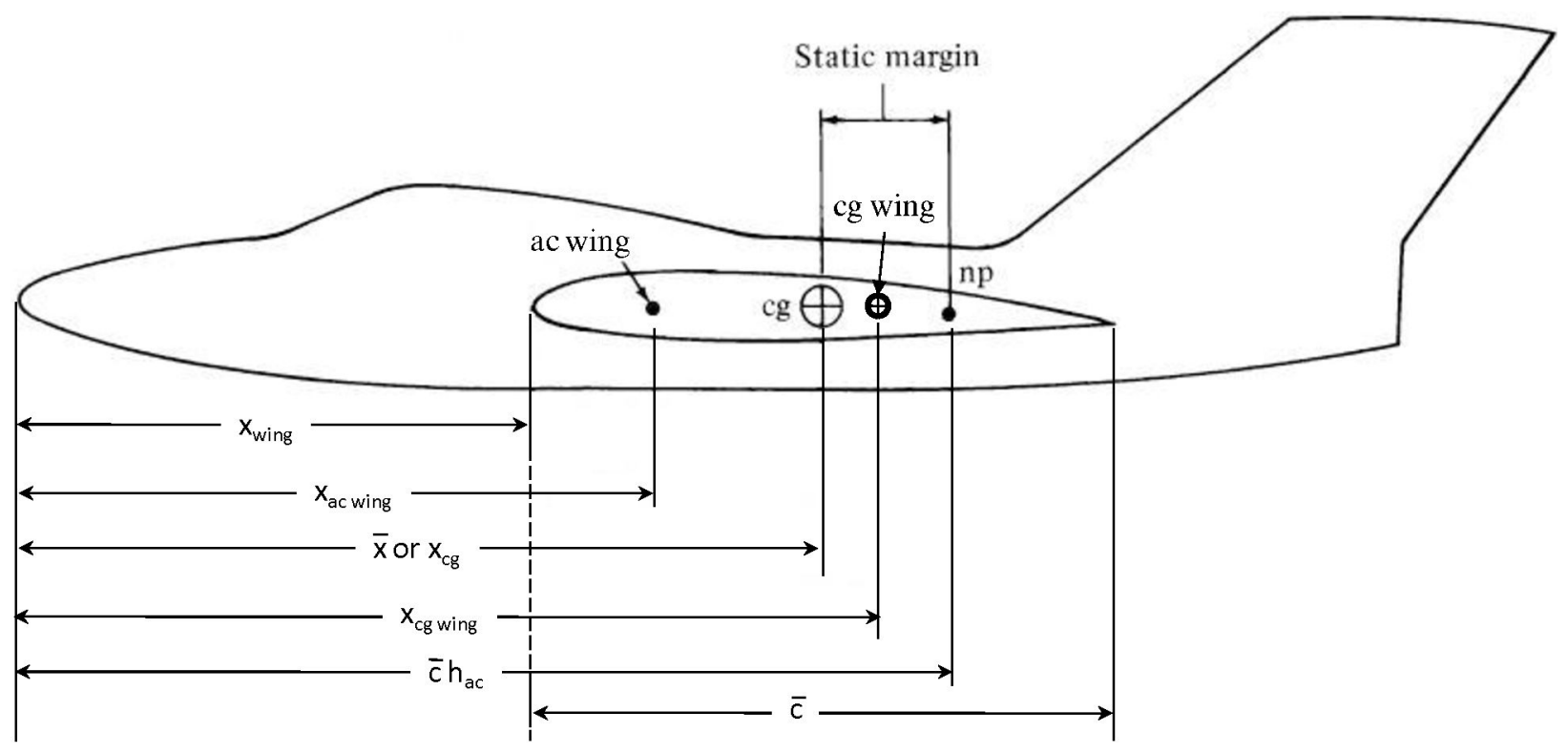

Figure 2: Wing Geometry

\section{Wing Center of Gravity}

$$
\begin{aligned}
& h_{\text {cg wing }}=\frac{x_{\text {wing }}+\frac{b}{6}\left(\frac{1+2 \lambda}{1+\lambda}\right) \tan \Lambda+\frac{1}{2} \bar{c}}{\bar{c}} \\
& x_{\text {cgwing }}=h_{\text {cg wing }} \bar{c}
\end{aligned}
$$

where

$\mathrm{h}_{\mathrm{cg} \text { wing }}$ is the non-dimensional distance from nose to wing's center of gravity

$\mathrm{X}_{\mathrm{cg} \text { wing }}$ is the distance from nose to wing's center of gravity (in) 


\section{Tail Section}

Assume the horizontal tail and vertical tails have the same taper ratio as the main wing.

$$
\lambda=\lambda_{\mathrm{HT}}=\lambda_{\mathrm{VT}}
$$

\section{Horizontal Tail Location}

To initially help ensure sufficient longitudinal stability we choose a larger tail volume ratio of 1.0 than traditional sailplanes which can be lowered later. Thus,

$$
V_{H T}=1.0=\frac{l_{H T} S_{H T}}{\bar{c} S}
$$

where

$\ell_{\mathrm{HT}} \quad$ is the distance from the airplane's center of gravity to the horizontal tail's aerodynamic center (in)

$\mathrm{S}_{\mathrm{HT}} \quad$ is the horizontal tail planform area $\left(\mathrm{in}^{2}\right)$

Solving for the horizontal tail planform area yields

$$
S_{H T}=\frac{\bar{c} S}{l_{H T}}
$$

where $\ell_{\mathrm{HT}}$ is a function of the center of gravity location from the below horizontal tail geometry. 


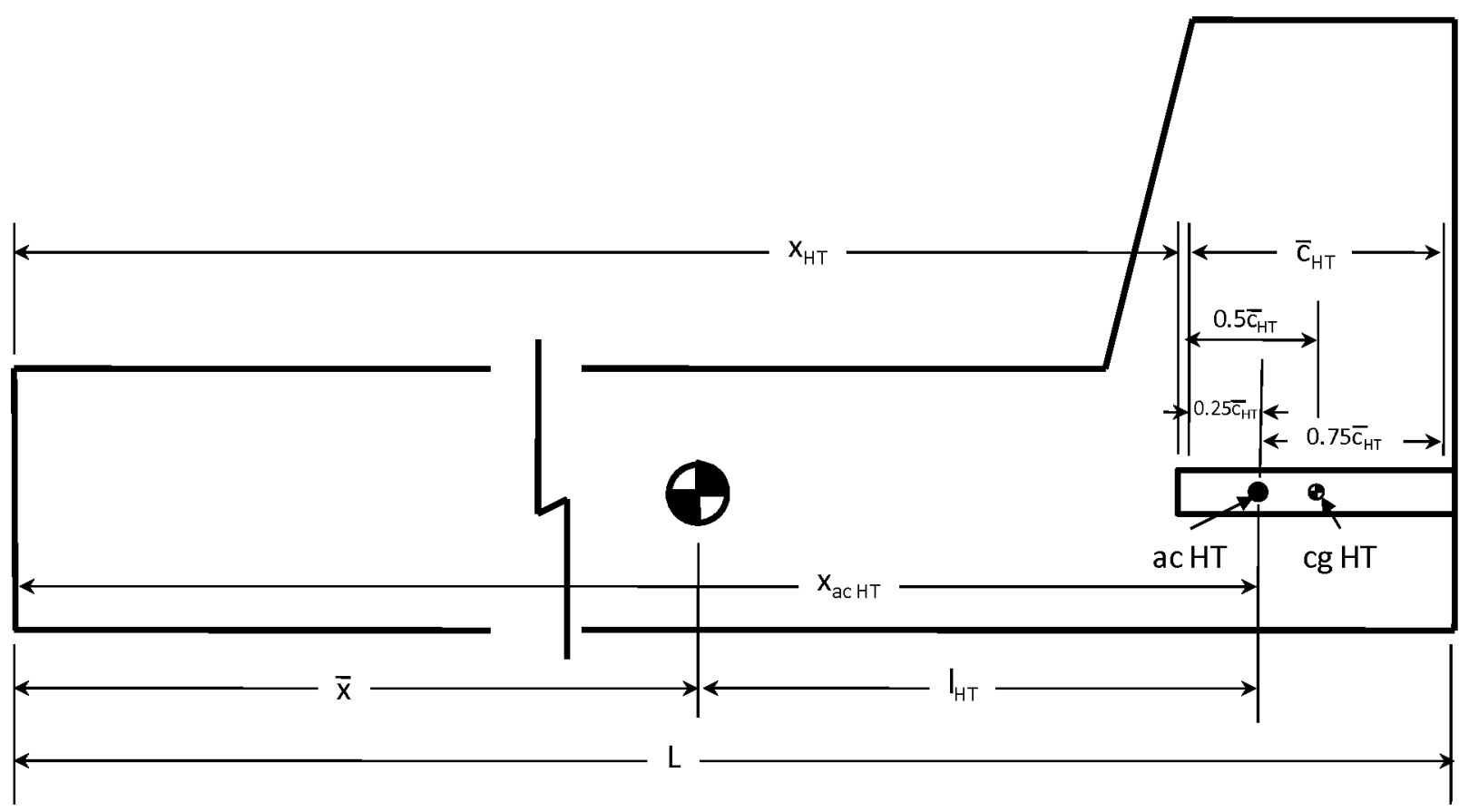

Figure 3: Horizontal Tail Geometry

Additionally, the location of the horizontal tail is important for construction and is approximately

$$
x_{H T}=\bar{x}+l_{H T}-0.25 \bar{c}_{H T}
$$

where

$$
\begin{array}{ll}
\mathrm{x}_{\mathrm{HT}} & \text { is the distance from the nose to the horizontal tail's leading edge (in) } \\
\bar{c}_{H T} & \text { is horizontal tail's mean aerodynamic chord length (in) }
\end{array}
$$

Also from the above horizontal tail geometry, the fuselage length can be approximated as

$$
L=\bar{x}+l_{H T}+0.75 \bar{c}_{H T}
$$

Thus,

$$
l_{H T}=L-\bar{x}-0.75 \bar{c}_{H T}
$$


and we can clearly see that $\ell_{\mathrm{HT}}$ is a function of the center of gravity location and horizontal tail mean chord length. As it turns out, the tail chord length itself is also a function of the center of gravity location. At this point in the design, however, we do not know enough to calculate the center of gravity location. This creates a circular equation where independent variables are really not independent of center of gravity location. To solve, an iterative approach is required where the initial guess for $\ell_{\mathrm{HT}}$ is

$$
l_{H T}=L-\bar{x}-0.2 L
$$

and the center of gravity is iterated by initially guessing

$$
\bar{x}=\frac{1}{g} L .
$$

\section{Horizontal Tail Geometry}

$$
\begin{aligned}
& A R_{H T}=\frac{1}{2} A R \\
& b_{H T}=\sqrt{S_{H T} A R_{H T}} \\
& c_{r_{H T}}=\frac{2 S_{H T}}{(\lambda+1) b_{H T}} \\
& c_{t_{H T}}=\lambda c_{r_{H T}} \\
& \bar{c}_{H T}=\frac{2}{3} c_{r_{H T}}\left(\frac{1+\lambda+\lambda^{2}}{1+\lambda}\right)
\end{aligned}
$$

where
$\mathrm{AR}_{H T}$
is horizontal tail aspect ratio
$b_{\mathrm{HT}}$
is horizontal tail span (in)
$\mathrm{C}_{\mathrm{rHT}}$
is horizontal tail root chord (in)
$\mathrm{c}_{\mathrm{t} \text { HT }}$
is horizontal tail tip chord (in) 


\section{Horizontal Tail Aerodynamic Center}

Note that Figure 3 assumes the horizontal tail's aerodynamic center occurs at the tail's quarter chord. Also from this figure, we can see that

$$
\begin{aligned}
& x_{a c_{H T}}=\bar{x}+l_{H T} \\
& h_{a c_{H T}}=\frac{x_{a c_{H T}}}{\bar{c}}
\end{aligned}
$$

where
$\mathbf{X}_{\mathrm{ac} \text { HT }}$
is distance from nose to horizontal tail's aerodynamic center (in)
$\mathrm{h}_{\mathrm{ac} \text { HT }}$ is non-dimensional distance from nose to horizontal tail's aerodynamic center
$\bar{c}$ is main wing mean chord (in)

\section{Vertical Tail Location}

For sufficient directional stability, the vertical tail volume ratio should be

$$
V_{V T}=0.04=\frac{l_{V T} S_{V T}}{b S}
$$

where

$\ell_{\mathrm{VT}}$ is the distance from the airplane's center of gravity to the vertical tail's aerodynamic center (in)

$\mathrm{S}_{\mathrm{VT}}$ is the vertical tail planform area $\left(\mathrm{in}^{2}\right)$ 
Solving for the vertical tail planform area yields

$$
S_{V T}=\frac{0.04 b S}{l_{V T}}
$$

where $\ell_{\mathrm{VT}}$ is a function of the center of gravity location from the below vertical tail geometry.

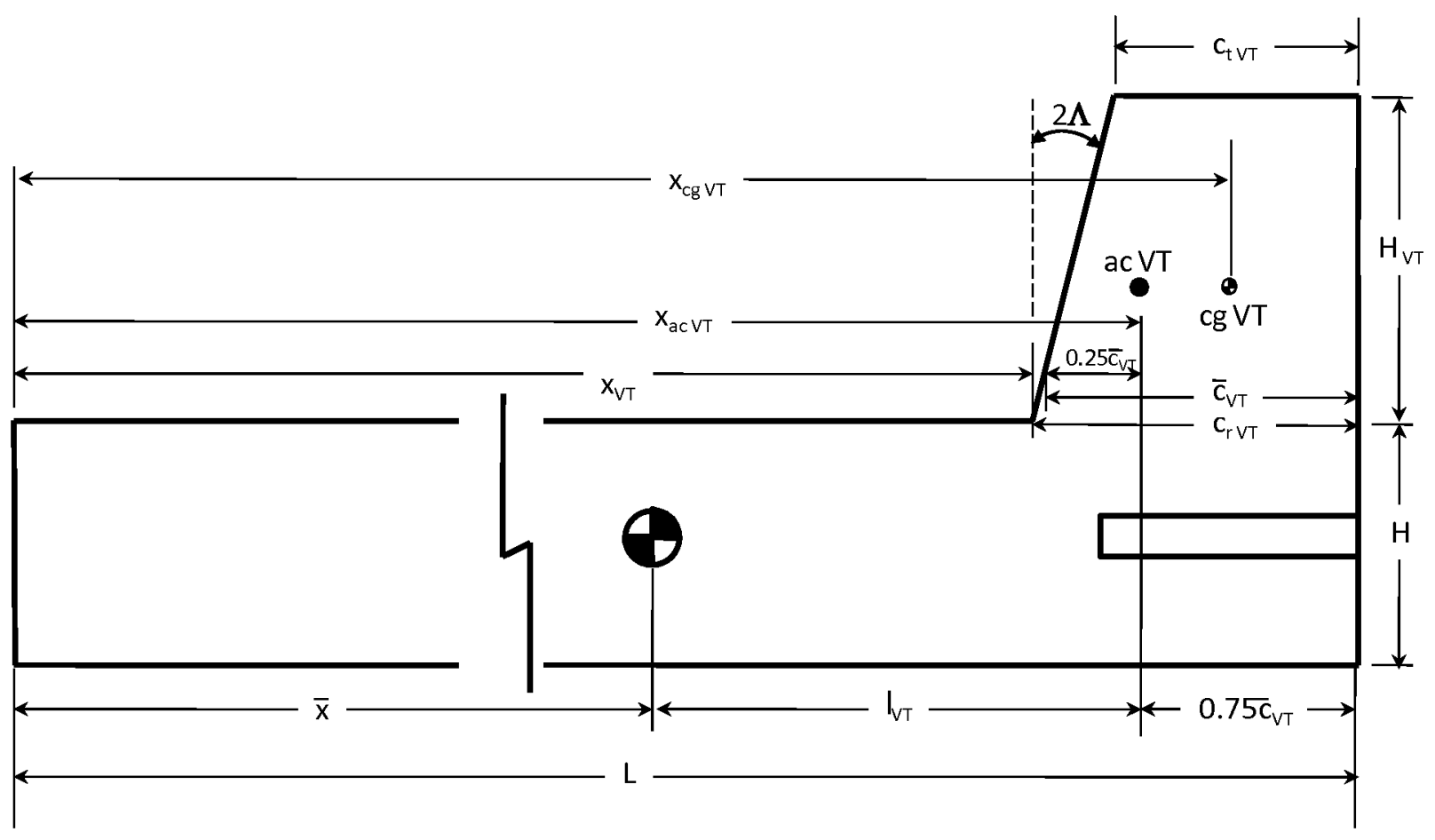

\section{Figure 4: Vertical Tail Geometry}

Additionally, the location of the vertical tail is important for construction and is approximately

$$
x_{V T}=\bar{x}+l_{V T}-0.25 \bar{c}_{V T}
$$

where

$$
\begin{aligned}
& \mathrm{X}_{\mathrm{VT}} \\
& \bar{c}_{V T} \quad \text { is the distance from the nose to the vertical tail's leading edge (in) } \\
& \text { is the vertical tail's mean aerodynamic chord length (in) }
\end{aligned}
$$

Also from the above vertical tail geometry, the fuselage length can be approximated as

$$
L=\bar{x}+l_{V T}+0.75 \bar{c}_{V T}
$$


Thus,

$$
l_{V T}=L-\bar{x}-0.75 \bar{c}_{V T}
$$

and we can clearly see that $\ell_{\mathrm{VT}}$ is a function of the center of gravity location and vertical tail mean chord length. As it turns out, the tail chord length itself is also a function of the center of gravity location. Again, at this point in the design, we do not know enough to calculate the center of gravity location. Just like with the horizontal tail, this creates a circular equation where independent variables are really not independent of center of gravity location. To solve, an iterative approach is required where the initial guess for $\ell_{\mathrm{VT}}$ is

$$
l_{V T}=L-\bar{x}-0.15 L
$$

and the center of gravity is iterated by initially guessing

$$
\bar{x}=\frac{1}{s} L
$$

\section{Vertical Tail Geometry}

Typically, the vertical tail aspect ratio falls between 1.3 and 2.0. We will treat the vertical tail ratio as a design parameter (see Section I) that is constrained between 1.3 and 2.0.

$$
\begin{aligned}
& H_{V T}=\sqrt{S_{V T} A R_{V T}} \\
& c_{r_{V T}}=\frac{2 S_{V T}}{(\lambda+1) H_{V T}} \\
& c_{t_{V T}}=\lambda c_{r_{V T}} \\
& \bar{c}_{V T}=\frac{2}{3} c_{r_{V T}}\left(\frac{1+\lambda+\lambda^{2}}{1+\lambda}\right)
\end{aligned}
$$

where
$\mathrm{AR}_{\mathrm{VT}}$
is the vertical tail aspect ratio 

$\mathrm{H}_{\mathrm{VT}}$
is the vertical tail height (in)
$\mathrm{c}_{\mathrm{r} \text { VT }}$
is the vertical tail root chord (in)
$\mathrm{c}_{\mathrm{t}} \mathrm{VT}$
is the vertical tail tip chord (in)

\section{Vertical Tail Aerodynamic Center}

Note that Figure 4 assumes the vertical tail's aerodynamic center occurs at the tail's quarter chord. Also from this figure, we can see that

$$
\begin{aligned}
& x_{a c_{V T}}=\bar{x}+l_{V T} \\
& h_{a c_{V T}}=\frac{x_{a c_{V T}}}{\bar{c}}
\end{aligned}
$$

where

$\begin{array}{ll}\mathrm{x}_{\mathrm{ac} V \mathrm{VT}} & \text { is the distance from nose to vertical tail's aerodynamic center (in) } \\ \mathrm{h}_{\mathrm{ac} \text { VT }} & \text { is the non-dimensional distance from nose to vertical tail's } \\ & \text { aerodynamic center } \\ \bar{c} & \text { is the main wing mean chord (in) }\end{array}$




\section{Center of Gravity}

At this point, we have enough to compute the first iterated center of gravity. The first step is to calculated the weight of each component

$$
\begin{aligned}
& \mathrm{W}_{\text {wing }}=\mathrm{St}_{\text {wing }} \rho_{\text {balsa }} \mathrm{g} \\
& \mathrm{W}_{\text {fuselage }}=\mathrm{LHt}_{\text {fuselag }} \rho_{\text {bal saa }} \mathrm{g} \\
& \mathrm{W}_{\mathrm{HT}}=\mathrm{S}_{\mathrm{HT}} \mathrm{t}_{\mathrm{HT}} \rho_{\text {ba lsa }} \mathrm{g} \\
& \mathrm{W}_{\mathrm{VT}}=\mathrm{S}_{\mathrm{VT}} \mathrm{t}_{\mathrm{VT}} \rho_{\text {balsag }} \mathrm{g} \\
& \mathrm{W}_{\text {balla st }}=\mathrm{m}_{\text {balla sta }} \mathrm{g} \\
& \Sigma \mathrm{W}=\mathrm{W}_{\text {wing }}+\mathrm{W}_{\text {fiselage }}+\mathrm{W}_{\mathrm{HT}}+\mathrm{W}_{\mathrm{VT}}+\mathrm{W}_{\text {ballast }}
\end{aligned}
$$

where

$$
\begin{aligned}
& \mathrm{t}_{\text {thin }}=2.0 \mathrm{~mm} \\
& \mathrm{t}_{\text {thick }}=3.5 \mathrm{~mm} \\
& \rho_{\text {balsa }}=1.572 \times 10^{-4} \frac{\text { slug }}{i n^{8}}
\end{aligned}
$$

NOTE: For the sample solution provided, the fuselage and vertical tail are thick and the wing and horizontal tail are thin. The mass of the ballast is dependent upon the selected coins. For the sample, 2 quarters are used.

The next step is to calculate the moment about the center of gravity contributed by each component. It is common to use the wing's leading edge as the reference point; however, in this case the location of the wing is a design parameter that may change. Therefore, we will use the 
nose as the reference point and sum moments about the nose. The moment for the wing and fuselage are fairly straight forward.

$$
\begin{aligned}
& M_{\text {wing }}=W_{\text {wing }} x_{\text {cg wing }} \\
& M_{\text {fuselage }}=W_{\text {fuselage }} \frac{L}{2}
\end{aligned}
$$

For the horizontal and vertical tails, assume the center of gravity of the tail sections occur at onehalf the mean chord. The moment arm for the tail section is the distance from the nose to the tail section plus the half the mean chord.

$$
\begin{aligned}
& M_{H T}=W_{H T}\left(x_{H T}+\frac{\bar{c}_{H T}}{2}\right) \\
& M_{V T}=W_{V T}\left(x_{V T}+\frac{\bar{c}_{V T}}{2}\right) \\
& M_{\text {ballast }}=W_{\text {ballast }} x_{\text {ballast }}
\end{aligned}
$$

The final moment is the moment created by the ballast (coins). The placement of the coins is at the designer's discretion. To provide the greatest stabilizing moment, move the coins forward. NOTE: For the sample solution, the coins are placed at the tip of the nose.

The total moment about the nose is the sum of each components moment

$$
\Sigma M_{\text {nose }}=M_{\text {wing }}+M_{\text {fuselage }}+M_{\mathrm{HT}}+M_{\mathrm{VT}}+M_{\text {ballast }}
$$

The center of gravity location, $\bar{x}$, is the distance from the nose to the average moment arm. The cg location is calculated the sum of the moments about the cg divided by the total weight.

$$
\overline{\mathrm{x}}=\frac{\Sigma \mathrm{M}_{\text {nose }}}{\Sigma \mathrm{W}}
$$


and

$$
h=\frac{\bar{x}}{\bar{c}}
$$

where

$\mathrm{h}$

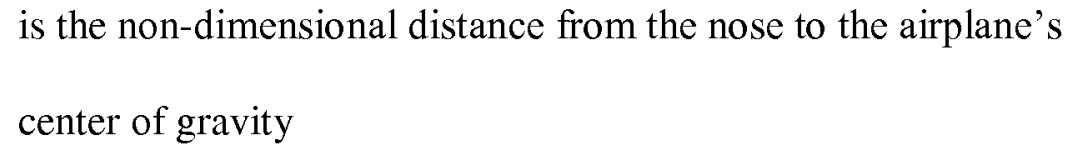

\section{Iteration}

Once the cg location is solved, the next loop of the iteration must recalculate $\ell_{\mathrm{HT}}$ and $\ell_{\mathrm{VT}}$ using

$$
\begin{aligned}
& l_{H T}=L-\bar{x}-0.75 \bar{c}_{H T} \\
& l_{V T}=L-\bar{x}-0.75 \bar{c}_{V T}
\end{aligned}
$$

Continue the iteration until the previous loop's calculated cg converges to the current loop's cg within 0.01 in. 


\section{$\underline{\text { V. Stability }}$}

\section{Aerodynamic Center}

The aerodynamic center of the lifting surfaces (wing and horizontal tail), or neutral point, is calculated from

$$
h_{a c}=\frac{h_{a c w i n g} a_{w i n g} q_{\infty} S+h_{a c H T} a_{H T} q_{\infty} S_{H T}}{a_{w i n g} q_{\infty} S+a_{H T} q_{\infty} S_{H T}}
$$

The lift curve slopes for the wing and horizontal tail are

$$
a_{\text {wing }}=\frac{2 \pi}{1+\frac{2 \pi}{\pi e A R}}
$$

and

$$
a_{H T}=\frac{2 \pi}{1+\frac{2 \pi}{\pi e_{H T} A R_{H T}}}
$$

where the Oswald Efficiency Factor of the main wing is

$$
e= \begin{cases}0.60, & \text { low wing } \\ 0.80, & \text { high wing }\end{cases}
$$

and for the horizontal tail is $\mathrm{e}_{\mathrm{HT}}=0.80$. Note: the sample solution is a high wing however recent literature presented in the 2010 Journal of Aircraft ${ }^{4}$ suggests that the Oswald Efficiency Factor is much lower, on the order of 0.20 to 0.30 for $\operatorname{Re}<5 \times 10^{5}$. Using these values may more accurately predict the ranges actually achieved by the gliders in the competition.

The dynamic pressure is defined as

$$
q_{\infty}=\frac{1}{2} \rho V_{\text {trim }}^{2}
$$


where

$\mathrm{V}_{\text {trim }} \quad$ is the equilibrium velocity. An average glider toss is constrained between $15 \mathrm{ft} / \mathrm{s}$ to $20 \mathrm{ft} / \mathrm{s}$.

\section{Static Margin}

The longitudinal static stability of the glider is measured with the static margin.

$$
\text { static margin }=h_{a \sigma}-h
$$

The moment curve slope can be calculated using the alternate expression for the static margin

$$
\text { static margin }=-a \frac{\partial C_{M_{c g}}}{\partial \alpha_{a}}
$$

where

$$
\text { is total airplane lift curve slope } a=a_{\text {wing }}\left(\frac{s}{s}\right)+a_{H T}\left(\frac{S_{H T}}{s}\right)
$$

NOTE: For sufficient positive longitudinal static stability, the static margin should be

$$
0.15 \leq \text { static margin } \leq 1.00
$$

Less than 0.15 will not provide sufficient stability in flight while greater than 1.00 results in an overly stable condition where the glider may not be able to generate enough pitch moment to stay in trim. 


\section{Drag}

The total drag on the glider is divided into zero lift drag and drag due to lift.

$$
\mathrm{C}_{\mathrm{D}}=\mathrm{C}_{\mathrm{D}, 0}+\mathrm{KC}_{\mathrm{L}}^{2}
$$

\section{Zero Lift Drag}

To calculate the zero lift drag, consider the skin friction over component surface area. The zero lift drag can be estimated over a flat plate as

\begin{tabular}{|c|c|c|c|}
\hline Component & Reynolds Number & Zero Lift Drag Coeff & Zero Lift Drag \\
\hline Wing & $\operatorname{Re}_{\text {wing }}=\frac{\rho_{\infty} \mathrm{V}_{\text {trim }} \overline{\mathrm{c}}}{\mu_{\infty}}$ & $C_{D o, \text { wing }}=\frac{1.328}{\sqrt{\operatorname{Re}_{\text {wing }}}}$ & $\mathrm{D}_{\mathrm{o} \text {,wing }}=\mathrm{C}_{\mathrm{Do}, \text { wing }} \mathrm{q}_{\infty} \mathrm{S}_{\text {wet, wing }}$ \\
\hline Fuselage & $\operatorname{Re}_{\text {fuselage }}=\frac{\rho_{\infty} \mathrm{V}_{\text {trim }} \mathrm{L}}{\mu_{\infty}}$ & $\mathrm{C}_{\mathrm{Do}, \text { fuselage }}=\frac{1.328}{\sqrt{\mathrm{Re}_{\text {fuselage }}}}$ & $D_{o \text {, fuselage }}=C_{D o, \text { fuselage }} \mathrm{q}_{\infty} S_{\text {wet, fuselage }}$ \\
\hline $\begin{array}{l}\text { Horizontal } \\
\text { Tail }\end{array}$ & $\operatorname{Re}_{\mathrm{HT}}=\frac{\rho_{\infty} \mathrm{V}_{\mathrm{trim}} \overline{\mathrm{c}}_{\mathrm{HT}}}{\mu_{\infty}}$ & $\mathrm{C}_{\mathrm{Do}, \mathrm{HT}}=\frac{1.328}{\sqrt{\operatorname{Re}_{\mathrm{HT}}}}$ & $\mathrm{D}_{\mathrm{o}, \mathrm{HT}}=\mathrm{C}_{\mathrm{Do}, \mathrm{HT}} \mathrm{q}_{\infty} \mathrm{S}_{\mathrm{wet}, \mathrm{HT}}$ \\
\hline Vertical Tail & $\operatorname{Re}_{\mathrm{VT}}=\frac{\rho_{\infty} \mathrm{V}_{\mathrm{trim}} \overline{\mathrm{c}}_{\mathrm{VT}}}{\mu_{\infty}}$ & $\mathrm{C}_{\mathrm{Do}, \mathrm{VT}}=\frac{1.328}{\sqrt{\mathrm{Re}_{\mathrm{VT}}}}$ & $\mathrm{D}_{\mathrm{o}, \mathrm{VT}}=\mathrm{C}_{\mathrm{Do}, \mathrm{VT}} \mathrm{q}_{\infty} \mathrm{S}_{\mathrm{wet}, \mathrm{VT}}$ \\
\hline
\end{tabular}

NOTE: The $S_{\text {wet }}$ is the wetted surface area of the body immersed in the fluid. Assume the wing, tail, and fuselage as two-dimension flat plates with two wetted sides to each component. For example, the wing has a wetted surface area twice that of the planform area $\left(S_{\text {wet }}=2 S\right)$. The same applies for the tail sections and fuselage. Additionally, we assume these equations based on laminar flow over the entire flat plate. Further refinement may be made by taking into 
account the fact that the flow over these components will be transitional and turbulent resulting in higher zero lift drag estimates which can attribute to lower than predicted maximum range performance.

The entire airplane's zero lift drag is the sum of the component zero lift drag.

$$
\mathrm{D}_{\mathrm{o}, \text { total }}=\mathrm{D}_{\mathrm{o}, \text { wing }}+\mathrm{D}_{\mathrm{o}, \text { fuselage }}+\mathrm{D}_{\mathrm{o}, \mathrm{HT}}+\mathrm{D}_{\mathrm{o}, \mathrm{VT}}
$$

The resulting zero lift drag coefficient is

$$
C_{\text {Do }}=\frac{D_{o, \text { total }}}{q_{\infty} S}
$$

\section{Drag Due to Lift}

The drag due to lift is equal to $\mathrm{KC}_{\mathrm{L}}^{2}$. The proportionality constant, $\mathrm{K}$, is

$$
\mathrm{K}=\frac{1}{\pi \mathrm{eAR}}
$$

Assuming lift equals weight in gliding flight, the coefficient of lift is

$$
\mathrm{C}_{\mathrm{L}}=\frac{\Sigma \mathrm{W}}{\mathrm{q}_{\infty} \mathrm{S}}
$$

NOTE: The maximum $\mathrm{C}_{\mathrm{L}}$ shall be 0.81 . This accounts for the maximum lift for a flat plate with 3D effects. You must change your design if $\mathrm{C}_{\mathrm{L}}$ is greater than 0.81 .

\section{Total Drag}

Now, the drag polar can be constructed to find the drag coefficient:

$$
\mathrm{C}_{\mathrm{D}}=\mathrm{C}_{\mathrm{D}, 0}+\mathrm{KC}_{\mathrm{L}}^{2}
$$




\section{Performance}

With the drag polar derived, the performance can now be estimated. The lift to drag

ratio, $\mathrm{L} / \mathrm{D}$, is found by:

$$
\frac{\mathrm{L}}{\mathrm{D}}=\frac{\mathrm{C}_{\mathrm{L}}}{\mathrm{C}_{\mathrm{D}}}
$$

The most important engineering characteristic of the glider is the range, $\mathrm{R}$, which is taken

from the lift to drag ratio

$$
\mathrm{R}=\frac{\mathrm{L}}{\mathrm{D}}(18 \mathrm{ft})
$$

where the average balcony launch height is 18 feet. The range is what needs to be optimized for the best glider design.. The descent glide angle, $\theta$, is

$$
\theta=\tan ^{-1} \frac{1}{\mathrm{~L} / \mathrm{D}}
$$

The endurance, E, can also be found by the equation:

$$
\mathrm{E}=\frac{\mathrm{R}}{\mathrm{V}_{\text {trim }}}
$$

The maximum lift to drag ratio is set by the drag polar as

$$
(\mathrm{L} / \mathrm{D})_{\max }=\sqrt{\frac{1}{4 \mathrm{KC}_{\mathrm{D}, 0}}}
$$

The minimum glide angle can then be found:

$$
\theta_{\text {min }}=\tan ^{-1} \frac{1}{(\mathrm{~L} / \mathrm{D})_{\max }}
$$

The velocity at the maximum lift to drag can be found as:

$$
\mathrm{V}_{(\mathrm{L} / \mathrm{D})_{\text {max }}}=\left(\frac{2}{\rho_{\infty}} \sqrt{\frac{\mathrm{K}}{\mathrm{C}_{\mathrm{D}, 0}}} \frac{\Sigma \mathrm{W}}{\mathrm{S}_{\text {wing }}}\right)^{1 / 2}
$$


Finally, the maximum range can be solved for as:

$$
\mathrm{R}_{\max }=(\mathrm{L} / \mathrm{D})_{\max }(18 \mathrm{ft})
$$

\section{Sample Solution}

Design Parameters

$\begin{array}{ll}\mathrm{L} & 20 \mathrm{in} \\ \mathrm{H} & 2 \mathrm{in} \\ \mathrm{b} & 20 \mathrm{in} \\ \mathrm{c}_{\mathrm{r}} & 3 \mathrm{in} \\ \lambda & 0.6 \\ \mathrm{X}_{\text {wing }} & 3.8 \mathrm{in} \\ \mathrm{x}_{\text {ballast }} & 0.4775 \mathrm{in} \\ \mathrm{m}_{\text {ballast }} & 11.34 \mathrm{~g} \text { total for } 2 \text { quarters } \\ \mathrm{AR}_{\mathrm{VT}} & 1.30 \\ \mathrm{~V}_{\text {trim }} & 16 \mathrm{ft} / \mathrm{s}\end{array}$

Main Wing

$\mathrm{x}_{\text {ac wing }} 4.69$ in

$\mathrm{x}_{\mathrm{cg} \text { wing }} 5.3$ in

Tail Sections

$\ell_{\mathrm{HT}} \quad 12.34$ in

$\ell_{\mathrm{VT}} \quad 12.31$ in

\section{Center of Gravity}

Thick wood fuselage, VT

Thin wood wing and HT

$\sum W \quad 0.0780 \mathrm{lbf}$

$\sum M \quad 0.507$ lbf-in

$\mathrm{x}_{\mathrm{cg}} \quad 6.50 \mathrm{in}$

\section{Drag}

$\operatorname{Re}_{\text {wing }} 20770$

$\mathrm{C}_{\text {Dwing }} 0.0092$

$\mathrm{D}_{\text {wing }} \quad 0.001870 \mathrm{lbf}$

$\mathrm{C}_{\text {Do }} \quad 0.02990$

$\begin{array}{ll}\mathrm{C}_{\mathrm{L}} & 0.769\end{array}$

\section{Performance}

L/D $\quad 13.23$

R $\quad 238.1 \mathrm{ft}$

$\mathrm{V}_{\mathrm{L} / \mathrm{Dmax}} 15.77 \mathrm{ft} / \mathrm{s}$ 


\section{APPENDIX B. Sample Spreadsheet Solution}

Design parameters from the glider methodology are highlighted in yellow. The iteration required between the center of gravity and the tail length is highlighted in magenta with the key performance parameters highlighted in green.

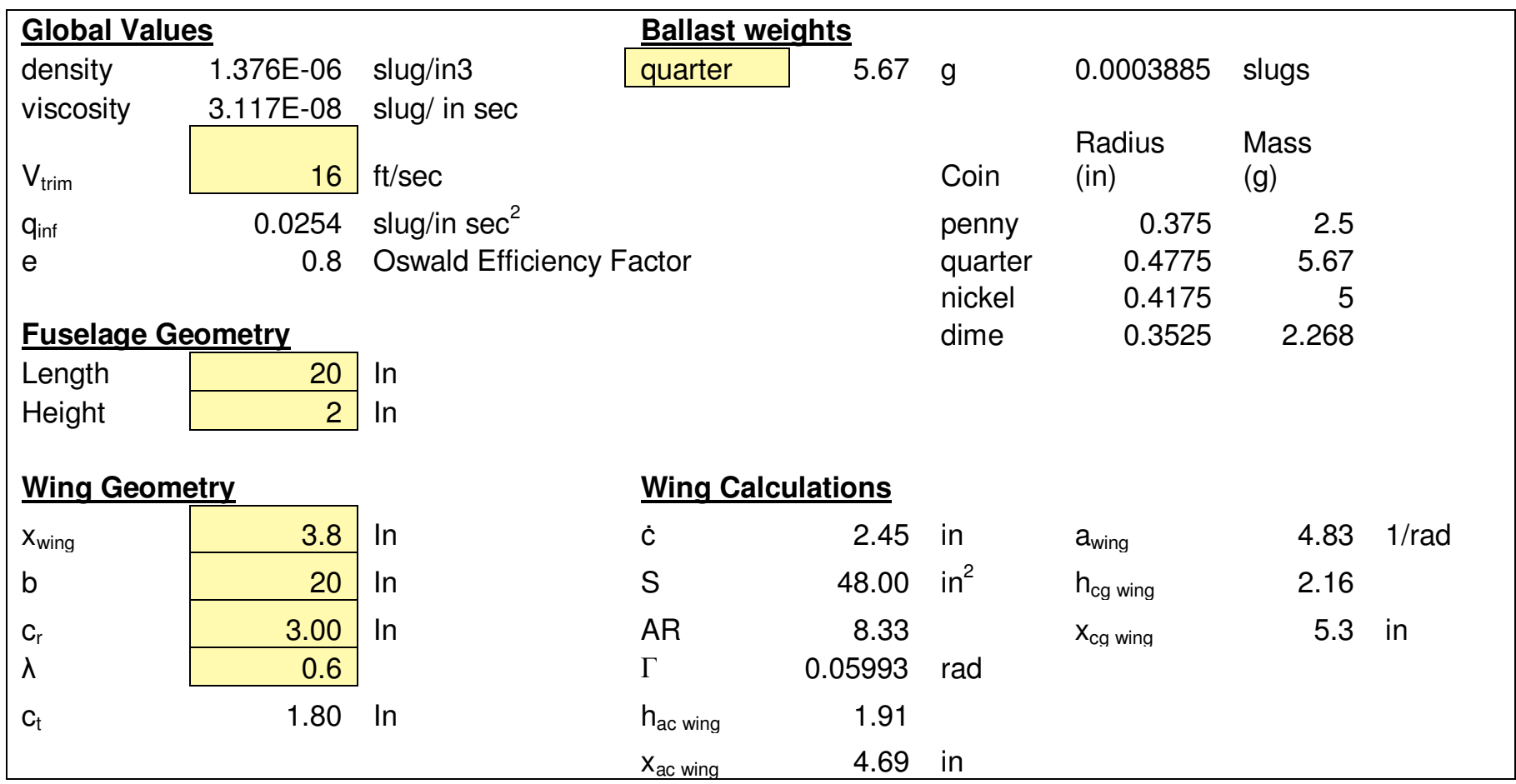

$\underline{\text { Tail Geometry }}$

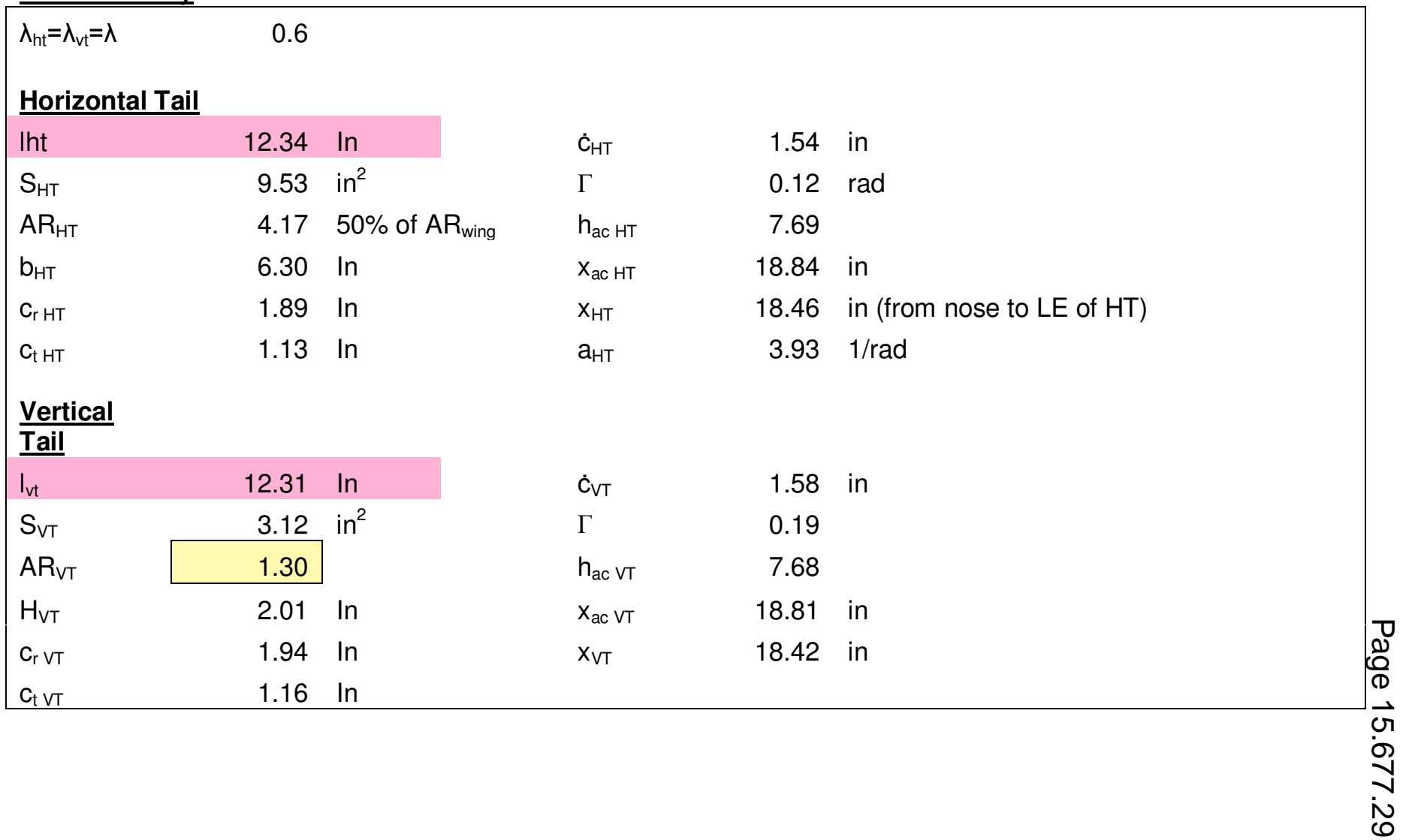




\section{CG Calculations}

\begin{tabular}{|c|c|c|c|c|c|c|c|c|c|}
\hline$\rho_{\text {wood }}$ & 0.0001572 & slug/in ${ }^{3}$ & & & & & & & \\
\hline Weights & & & & Moments & & & & & \\
\hline$W_{\text {fuselage }}$ & 0.027900 & Lbf & $\begin{array}{l}\text { thick } \\
\text { balsa } \\
\text { thin }\end{array}$ & $\mathrm{M}_{\text {fuselage }}$ & 0.27900 & in-lbf & & & \\
\hline $\mathrm{W}_{\text {wings }}$ & 0.019131 & Lbf & $\begin{array}{l}\text { balsa } \\
\text { thin }\end{array}$ & $M_{\text {wings }}$ & 0.10140 & in-lbf & & & \\
\hline$W_{\text {HT }}$ & 0.003798 & Lbf & $\begin{array}{l}\text { balsa } \\
\text { thick }\end{array}$ & $\mathrm{M}_{\mathrm{HT}}$ & 0.07302 & in-lbf & & & \\
\hline $\mathrm{W}_{\mathrm{VT}}$ & 0.002175 & Lbf & balsa & $\mathrm{M}_{\mathrm{VT}}$ & 0.04178 & in-lbf & & & \\
\hline$W_{\text {Ballast }}$ & 0.025020 & Lbf & 2 coins & $M_{\text {Ballast }}$ & 0.01195 & in-lbf & $X_{\text {Ballast }}$ & 0.4775 & in \\
\hline & & & & & & & & 0.4775 & in \\
\hline \multirow[t]{2}{*}{ Wtotal } & 0.078023 & Lbf & & M total & 0.50714 & in-lbf & & & \\
\hline & & x_bar & 6.50 & & & & & & \\
\hline
\end{tabular}

\begin{tabular}{|lllr|}
\hline Stability & & & \\
$\mathrm{h}$ & 2.65 & $\partial \mathrm{C}_{\mathrm{Mcg}} / \partial \alpha$ & -0.352 \\
$\mathrm{~h}_{\mathrm{ac}}$ & 2.72 & $\mathrm{SM}$ & 0.06 \\
$\mathrm{a}_{\text {aircraft }}$ & 5.61 & & \\
\hline
\end{tabular}

\section{Drag Polar}

Calculations

\begin{tabular}{|c|c|c|c|c|c|c|c|c|}
\hline \multicolumn{2}{|l|}{ Wing } & \multicolumn{2}{|c|}{ Fuselage } & \multicolumn{3}{|c|}{ Horizontal Tail } & \multicolumn{2}{|c|}{ Vertical Tail } \\
\hline $\mathrm{Re}$ & 20770.41 & $\mathrm{Re}$ & 169554.37 & $\mathrm{Re}$ & 13087.14 & & $\mathrm{Re}$ & 13403.63 \\
\hline$C_{D, \text { wing }}$ & 0.0092 & $C_{D, f u s e}$ & 0.0032 & $\mathrm{C}_{\mathrm{D}, \mathrm{HT}}$ & 0.0116 & & $C_{D, V T}$ & 0.0115 \\
\hline $\mathrm{S}_{\text {wet, wing }}$ & $96.00 \mathrm{in}^{2}$ & $S_{\text {wet,fuse }}$ & $80.00 \mathrm{in}^{2}$ & $\mathrm{~S}_{\text {wet }, H T}$ & 19.06 & $\mathrm{in}^{2}$ & $\mathrm{~S}_{\text {wet, } \mathrm{VT}}$ & $6.24 \mathrm{in}^{2}$ \\
\hline$D_{\text {wing }}$ & $0.001870 \quad \mathrm{lbf}$ & $D_{\text {fuse }}$ & $0.00055 \mathrm{lbf}$ & $\mathrm{D}_{\mathrm{HT}}$ & 0.00047 & lbf & $\mathrm{D}_{\mathrm{VT}}$ & $0.00015 \mathrm{lbf}$ \\
\hline
\end{tabular}

\begin{tabular}{|c|c|c|c|c|}
\hline $\begin{array}{l}\text { Zero Lift } \\
\text { Drag }\end{array}$ & $0.00303 \mathrm{lbf}$ & $C_{\text {Do }}$ & 0.02990 & \\
\hline k & 0.048 & & & \\
\hline $\mathrm{C}_{\mathrm{L}}$ & 0.769 & $C_{D}$ & 0.0581 & $\begin{array}{l}\text { Based on trim } \\
\text { velocity }\end{array}$ \\
\hline
\end{tabular}

\section{Predicted}

Performance

\begin{tabular}{|c|c|c|c|c|}
\hline L/D & 13.23 & $\mathrm{~L} / \mathrm{D}_{\max }$ & 13.232 & \\
\hline$\theta$ & 0.08 & $\theta_{\min }$ & 0.0754286 & $\mathrm{rad}$ \\
\hline Endurance & $14.88 \mathrm{sec}$ & $V_{\text {L/Dmax }}$ & 15.77 & $\mathrm{ft} / \mathrm{sec}$ \\
\hline Range & $238.09 \mathrm{ft}$ & $\begin{array}{l}\text { Max } \\
\text { Range }\end{array}$ & 238.18354 & \\
\hline
\end{tabular}




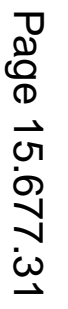

